\title{
Investigating the Significance of Aerosols in Determining the Coronavirus Fatality Rate Among Three European Countries
}

\author{
Wenzhao $\mathrm{Li}^{1} \cdot$ Rejoice Thomas ${ }^{2} \cdot$ Hesham El-Askary ${ }^{1,3,4}$ (1) $\cdot$ Thomas Piechota ${ }^{1} \cdot$ Daniele Struppa ${ }^{1}$. \\ Khaled A. Abdel Ghaffar ${ }^{5}$
}

Received: 13 August 2020 / Accepted: 28 August 2020 / Published online: 20 September 2020

(c) The Author(s) 2020

\begin{abstract}
The coronavirus pandemic has not only gripped the scientific community in the search for a vaccine or a cure but also in attempts using statistics and association analysis-to identify environmental factors that increase its potency. A study by Ogen (Sci Total Environ 726:138605, 2020a) explored the possible correlation between coronavirus fatality and high nitrogen dioxide exposure in four European countries-France, Germany, Italy and Spain. Meanwhile, another study showed the importance of nitrogen dioxide along with population density in determining the coronavirus pandemic rate in England. In this follow-up study, Aerosol Optical Depth (AOD) was introduced in conjunction with other variables like nitrogen dioxide and population density for further analysis in fifty-four administrative regions of Germany, Italy and Spain. The AOD values were extracted from the Moderate Resolution Imaging Spectroradiometer (MODIS) onboard the Terra and Aqua satellites while the nitrogen dioxide data were extracted from TROPOMI (TROPOspheric Monitoring Instrument) sensor onboard the Sentinel-5 Precursor satellite. Regression models, as well as multiple statistical tests were used to evaluate the predictive skill and significance of each variable to the fatality rate. The study was conducted for two periods: (1) pre-exposure period (Dec 1, 2019-Feb 29, 2020); (2) complete exposure period (Dec 1, 2019-Jul 1, 2020). Some of the results pointed towards AOD potentially being a factor in estimating the coronavirus fatality rate. The models performed better using the data collected during the complete exposure period, which showed higher AOD values contributed to an increased significance of AOD in the models. Meanwhile, some uncertainties of the analytical results could be attributed to data quality and the absence of other important factors that determine the coronavirus fatality rate.
\end{abstract}

Keywords COVID-19 - Coronavirus · Population density $\cdot$ Aerosol optical depth (AOD) $\cdot$ Nitrogen dioxide $\left(\mathrm{NO}_{2}\right)$. Sentinel-5P

\section{Introduction}

Electronic supplementary material The online version of this article (https://doi.org/10.1007/s41748-020-00176-4) contains supplementary material, which is available to authorized users.

Hesham El-Askary

elaskary@chapman.edu

1 Schmid College of Science and Technology, Chapman University, 1 University Drive, Orange, CA 92866, USA

2 Computational and Data Sciences Graduate Program, Schmid College of Science and Technology, Chapman University, Orange, CA 92866, USA

3 Center of Excellence in Earth Systems Modeling and Observations, Chapman University, Orange, CA 92866, USA
In December 2019, many cases of pneumonia were reported in Wuhan, China. The subsequent investigation revealed the cause to be a novel coronavirus, which was later called

4 Department of Environmental Sciences, Faculty of Science, Alexandria University, Moharem Bek, Alexandria 21522, Egypt

5 Ministry of Higher Education and Scientific Research, Cairo, Egypt 
2019 novel coronavirus (SARS-Cov-2) or more commonly, the COVID-19 (Barcelo 2020). The virus that originated in China then spread across the world, becoming a global pandemic and affecting millions worldwide. According to Worldometers (https://www.worldometers.info/), the death count (as of Aug 24, 2020) due to the COVID-19 has surpassed 810,000 , a number that probably underestimates the actual count, due to reporting issues (Lachmann et al. 2020; Cohen 2020; Bendix 2020). Though no vaccine is available yet (primarily due to the long time required for testing), studies continue in full flow (Lawton 2020; Mamedov et al. 2020). Apart from working to develop a vaccine, many researchers have investigated other factors that might impact coronavirus fatality. There are studies to evaluate the non-pharmaceutical interventions (NPI) such as social distancing, response of relevant agencies during the disease spread (Masrur et al. 2020; Li et al. 2020; Lai et al. 2020). Some of the other factors being studied include arctic oscillation (Sanchez-Lorenzo et al. 2020), air quality and wealth (Antonietti et al. 2020; Nichol et al. 2020), particulate matter pollution (Setti et al. 2020), diabetes (Means 2020), wind speeds (Coccia 2020), and ultraviolet radiation (Carleton et al. 2020), to name a few.

One of the environmental factors that received wide attention was nitrogen dioxide $\left(\mathrm{NO}_{2}\right)$ reported by Ogen (2020a). That paper found that $\mathrm{NO}_{2}$ has a strong association with a high fatality rate of COVID-19 cases. The four countries selected in that study were France, Germany, Italy and Spain. However, Chudnovsky (2020) pointed out that Ogen's study did not consider data of other factors that determine COVID-19 fatality and suggested that population density considerations would be important for a comprehensive analysis. Meanwhile, a response published by Ogen (2020b) agreed that the work did not prove any causality between $\mathrm{NO}_{2}$, and the fatality caused by COVID-19; rather the study was meant to establish an idea and would need further exploration. An association analysis relating $\mathrm{NO}_{2}$ and population density to COVID-19 fatality has been done by at least one other study, by Travaglio et al. (2020). They found that both these variables are significantly related to
COVID-19 fatality. Following up on these investigations, this study brings $\mathrm{NO}_{2}$, population density and aerosol optical depth (AOD) into the analysis, which attempts to see if adding AOD to the model, along with $\mathrm{NO}_{2}$ and population density, improves its predictive skill.

Fifty-four administrative regions from three European countries (Germany, Italy and Spain) are investigated in this study. France was not included, since the total number of positive coronavirus cases per region in France was not available in time for our purposes; only the number of hospitalized cases per region was recorded. The European Environment Agency recorded around 76,200 premature deaths due to bad air quality in Italy, 73,900 in Germany and 33,300 in Spain for the year 2016 (EEA 2019). The population in these countries is thus exposed to air pollution which gives rise to adverse health impacts and getting worsened when infected by the coronavirus. In this paper, several tools such as AOD maps and regression models were used to explore the possible relationship between $\mathrm{NO}_{2}$, population densities, AOD, and the fatality rate of COVID-19 in the selected regions. This study is divided into two main parts-(1) pre-exposure period and (2) complete exposure period. During the pre-exposure period, $\mathrm{NO}_{2}$ and $\mathrm{AOD}$ were extracted during a time before the coronavirus fatalities were at their peak, that is, Dec 1, 2019-Feb 29, 2020. The hypothesis here is that pre-exposure may worsen the health conditions that are critical to the chances of survival after getting infected. During the complete exposure period, the $\mathrm{NO}_{2}$ and AOD data within the same time frame as the coronavirus fatalities were also included (Mar 1, 2020-Jul 1, 2020), along with the data from the pre-exposure period. This is based on the understanding that $\mathrm{NO}_{2}$ and AOD would be impacted during COVID-19 timelines due to human efforts such as lockdowns. Figure 1 is a diagram that displays some of the factors expected to impact the transmission of the virus, including weather conditions, human activities, and population density. There are several relationships open to be explored, such as the environment's influence on the concentrations of $\mathrm{NO}_{2}$ and AOD, air pollutant's relationship to the fatality rate, as well as human activities' impact on the
Fig. 1 A diagram to show the environmental factors in the pandemic

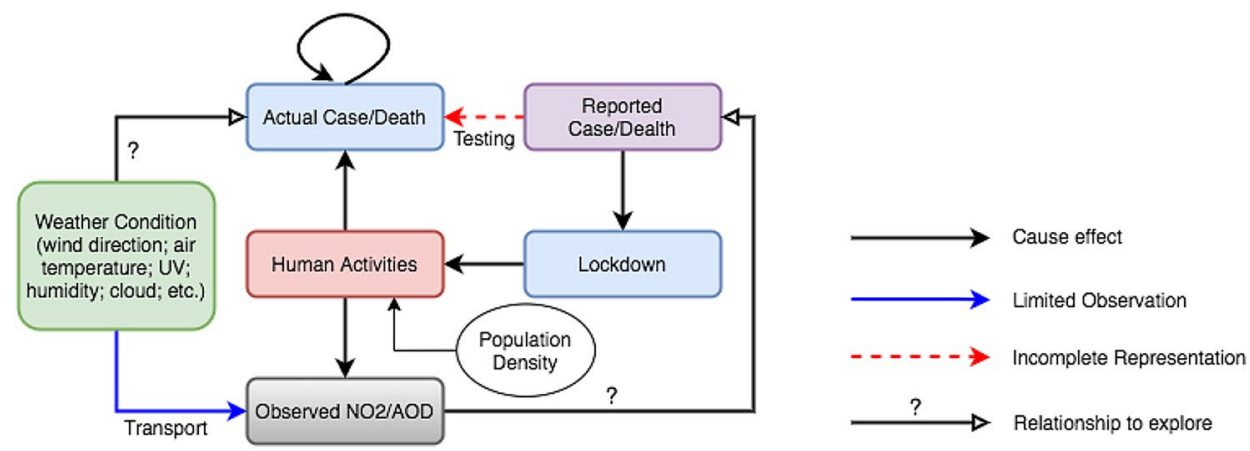


emissions of air pollutant. This study tests the hypothesis that aerosols are an important factor in coronavirus transmission rate (Asadi et al. 2020; Guo et al. 2020), which in turn would impact the coronavirus fatalities.

\section{Materials and Methods}

\subsection{Data}

\subsubsection{The COVID-19 Fatality Data and Population Density Data}

The COVID-19 fatality data were taken until Jul 1, 2020. For Italy, the COVID-19 fatality numbers per region were taken from the GitHub account (https://github.com/pcmdpc/COVID-19) of the Department of Civil Protection, Italy. For Germany, data published by the Robert Koch Institute (https://www.rki.de/DE/Content/InfAZ/N/Neuartiges_Coron avirus/Situationsberichte/Gesamt.html) was used. For Spain, data maintained by the New York Times (https://www.nytim es.com/interactive/2020/world/europe/spain-coronaviru s-cases.html) was used, who in turn retrieved it from the Spanish Ministry of Health. The death rate is calculated as the total number of coronavirus related deaths per region divided by the total number of coronavirus positive cases. For the regression models, the data for population density corresponding to each region was derived from the "citypopulation" program (https://www.citypopulation.de/). The "WorldPop Project Population Data" (www.worldpop. org) dataset retrieved by the Google Earth Engine platform (Gorelick et al. 2017) was used to show the population density distribution for the selected countries. The WorldPop dataset depicts the estimated number of people residing in each $1 \mathrm{~km} \times 1 \mathrm{~km}$ grid cell.

\subsection{2 $\mathrm{NO}_{2}$ Data}

$\mathrm{NO}_{2}$ data were obtained from the onboard sensor, TROPOMI, on Sentinel-5 Precursor satellite version Near RealTime (NRTI) (Veefkind et al. 2012). The data were collected and processed, from Dec 1, 2019 to Jul 1, 2020.

\subsubsection{AOD data}

The daily AOD data (Level 2, 1-km resolution) were obtained from MODIS Terra and Aqua using Multi-angle Implementation of Atmospheric Correction (MAIAC) (Lyapustin and Wang 2018). The green band (Optical_Depth_055) was used to extract the values and the cloudy pixels were masked for better quality. Like $\mathrm{NO}_{2}$, the data were collected and processed (e.g. filtered to remove the low-quality observations) from Dec 1, 2019 to Jul 1, 2020.

\subsection{Method}

To assess the significance of AOD in predicting the COVID-19 fatality rate, a linear regression model was fit to the data, followed by use of the stepAIC() function from the MASS package (Venables and Ripley 2002) in R. The stepAIC() function performs stepwise model selection using AIC (Akaike information criterion) as the criterion for selection. Along with improving the model performance, this function helps to simplify a model through feature selection. This function also penalizes the model if more variables are added (Tripathi2019) and thus, is a good technique to determine whether an unrestricted model (having $\mathrm{NO}_{2}$, Population Density and AOD as independent variables) is better than a restricted model (having only $\mathrm{NO}_{2}$ and Population Density as independent variables). This helps to evaluate the significance of the third variable; AOD in this instance. The direction of the stepwise model selection is backward.

A beta regression model (Cribari-Neto and Zeileis 2009) was also fit to the data, given that the fatality rate lay in the standard unit interval of $(0,1)$. The beta regression model provides good flexibility, which is delivered by the assumed beta law. The beta density assumes several different shapes that depend on the combination of parameter values, including left- and right-skewed, or the flat shape of uniform density. To assess the performance of the nested beta regression models (restricted model without AOD and unrestricted model including AOD), Wald test and Likelihood Ratio test were performed from the "Imtest" package (Zeileis and Hothorn 2002) in R. The Wald test statistic is given by,

$W_{\mathrm{T}}=I_{\mathrm{n}}(\hat{\theta})\left[\hat{\theta}-\theta_{0}\right]^{2}$,

where $\hat{\theta}$ is the maximum likelihood estimator (MLE) and $I_{\mathrm{n}}(\hat{\theta})$ is the expected Fisher information (evaluated at the MLE) (Stephanie 2016a). The likelihood ratio test statistic is given by,

$\mathrm{LRT}=\log _{\mathrm{e}}\left(\frac{L_{\mathrm{s}}(\hat{\theta})}{L_{\mathrm{g}}(\hat{\theta})}\right)$,

where $L_{\mathrm{s}}(\hat{\theta})$ and $L_{\mathrm{g}}(\hat{\theta})$ are log-likelihood functions for the two models (Stephanie 2016b). These are statistical tests to evaluate the significance of variables and compare the goodness of fit between two nested (generalized) linear models. 


\section{Results}

\subsection{Distribution of Population in the Three Countries}

The boxplots shown in Fig. 2 display the distributions of population density of Italy, Spain and Germany, with the $y$-axis showing the population per $1 \mathrm{~km}^{2}$ pixel. The histogram shares the same $y$ axis with boxplot, with its $x$ axis representing the number of pixels (equal to the areas in $\mathrm{km}^{2}$ ) having the same population values. Among these countries, Germany and Italy have similar median population densities $\left(\sim 30\right.$ people per $\left.1 \mathrm{~km}^{2}\right)$, which are much higher than Spain $\left(<10\right.$ people per $\left.1 \mathrm{~km}^{2}\right)$. Italy has a wider interquartile range (the IQR between 25 th and 75 th percentiles is shown between the upper and lower boundary of the box) than Germany and Spain have, indicating a more uniform distribution of population density in Italy. The cutoff outlier values defined for Germany, Italy and Spain are approximately $1000,10,000$ and 400 people per $1 \mathrm{~km}^{2}$, respectively. However, both Italy and Spain have a wider range of entire population density (from near 1 to over 10,000 people per $1 \mathrm{~km}^{2}$ ) than Germany. Therefore, it is concluded that: (1) Germany is mainly constituted with medium populated areas (10-1000 people per $1 \mathrm{~km}^{2}$ ), with limited areas of both densely (>1000 people per $1 \mathrm{~km}^{2}$ ) and sparsely (near 1 person per $1 \mathrm{~km}^{2}$ ) populated areas, yet having no overcrowded area $(>10,000$ people per $\left.1 \mathrm{~km}^{2}\right)$; (2) Italy has a more evenly distributed population, having both sparsely (near 1 person per $1 \mathrm{~km}^{2}$ ) and densely ( $>1000$ people per $1 \mathrm{~km}^{2}$ ) populated areas, as well as some overcrowded areas ( $>10,000$ people per $\left.1 \mathrm{~km}^{2}\right)$; (3) Spain has a skewed distribution with many areas having a limited population (near 1 person per $1 \mathrm{~km}^{2}$ ), while also having overcrowded areas $\left(>10,000\right.$ people per $\left.1 \mathrm{~km}^{2}\right)$.

\subsection{Spatial Distributions of AOD during Pre-Exposure Period}

Figure 3 displays spatial distributions of AOD in the atmosphere for Italy, Germany and Spain. The time frame is from Dec 1, 2019 to Feb 29, 2020, which is the pre-exposure period.

By observing the maps alone, we can see Germany has higher values of AOD compared to Italy and Spain. Northern Italy, Southern Spain as well as the Canary and Balearic Islands of Spain all have relatively high AOD values.

\subsection{Regression Analysis During Pre-Exposure Period for $\mathrm{NO}_{2}$ and AOD}

For the linear and beta regression models, data from 54 administrative regions of Italy (20 regions), Germany (16 regions) and Spain (18 regions) were used. Individual countries, and countries coupled with each other, were also evaluated to compare the results. For each combination, two models were generated: one, with $\mathrm{NO}_{2}$ and Population Density as independent variables, and another with $\mathrm{NO}_{2}$, Population Density, and AOD as independent variables. For a specific
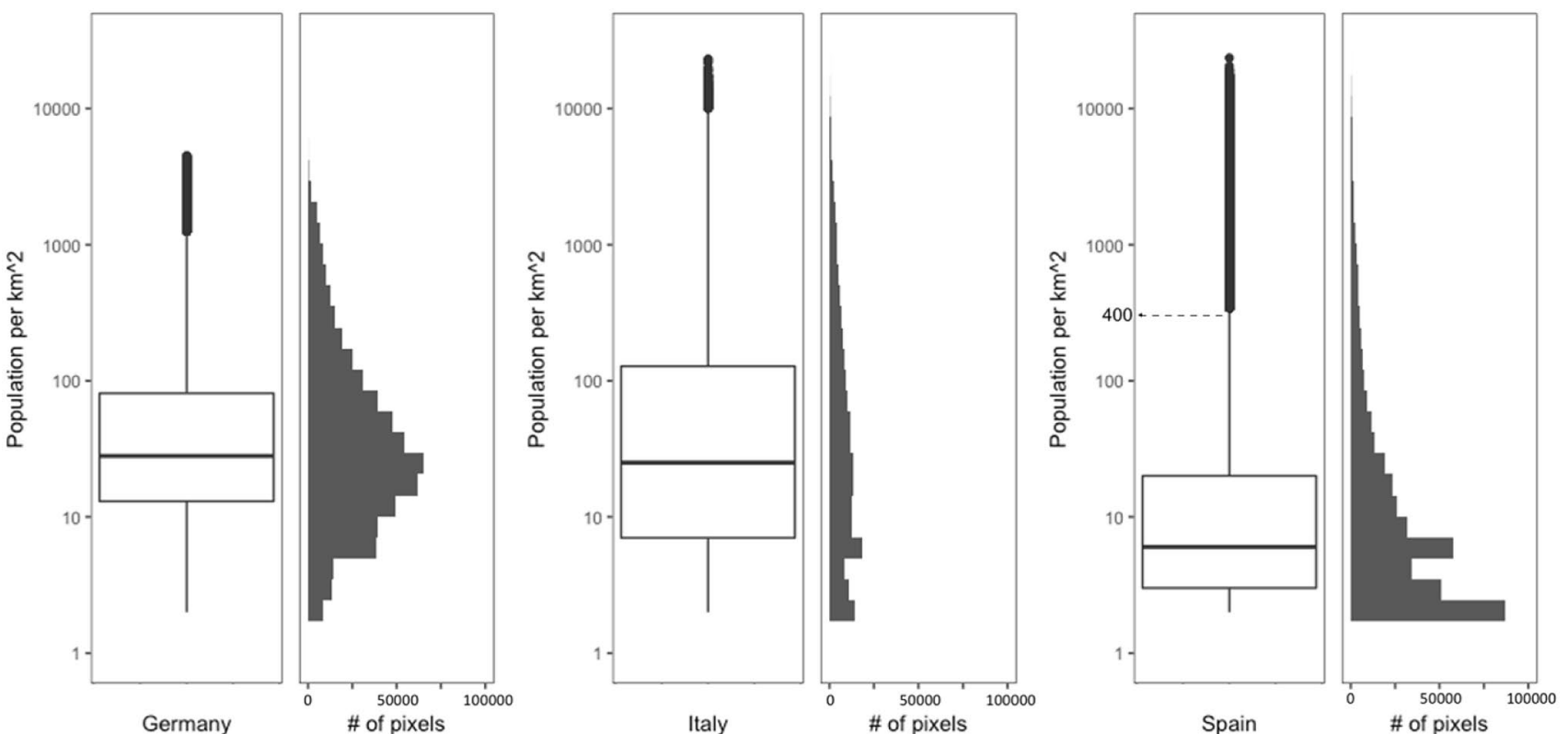

Fig. 2 Boxplot and histograms depicting the population densities of Italy, Spain and Germany (pixels of population less than 1 person per km ${ }^{2}$ are not included) 

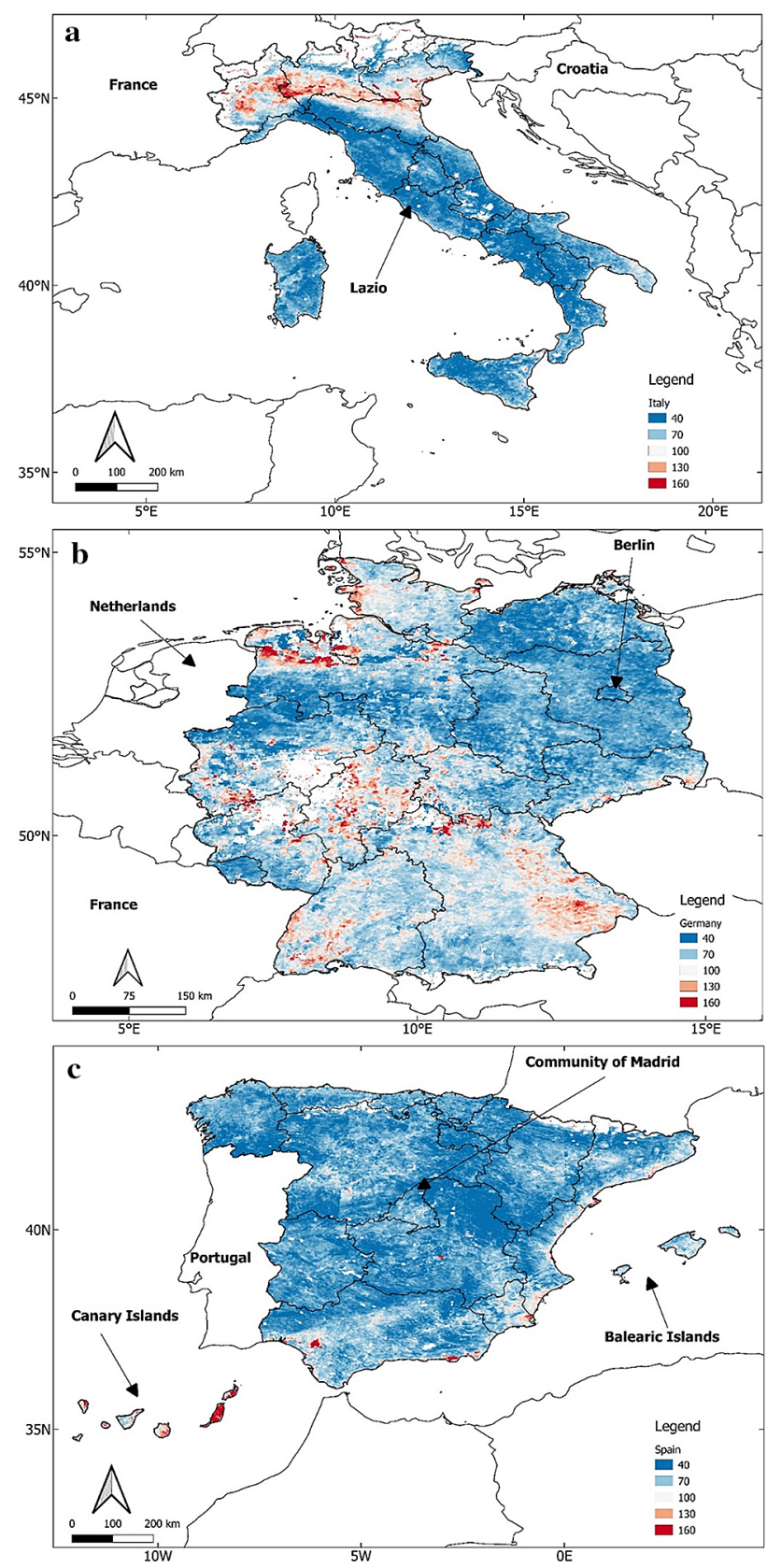

Fig. 3 Spatial Distributions of AOD extracted from MODIS for all regions in aa Italy; b Germany; c Spain; for the pre-exposure period (Dec 1, 2019-Feb 29, 2020). The scale factor is 0.001. The actual AOD values displayed in the figure are in the range of $0.04-0.16$. For Spain (c), the Canary Islands have been moved to fit in the figure

combination, a decrease in the AIC value or an increase in the adjusted $R^{2}$ value determines the significance of the added variable (AOD). The stepAIC() function also helps in identifying the most important variables with the best (lowest) AIC value. Table 1 compares AIC, adjusted $R^{2}$, and the variables which are considered most important by the stepAIC() function after the stepwise model selection.
From the results, we can observe that AOD is a significant variable in 3 of the 7 models while in the others it is not. Some of the models have low adjusted $R^{2}$ values, but for the models where AOD is found to be a significant predictor, the adjusted $R^{2}$ values are relatively high $(>0.4)$. In those cases, there is an increase in the adjusted $R^{2}$ value when compared to its restricted $\left(\mathrm{NO}_{2}+\mathrm{PD}\right)$ counterpart. This increase in adjusted $R^{2}$ value for the unrestricted model $\left(\mathrm{NO}_{2}+\mathrm{PD}+\mathrm{AOD}\right)$ suggests that the addition of AOD makes a significant contribution to that model. When Italy, Germany and Spain are included together (Italy + Germany + Spain), population density appears to be the most significant variable. The stepAIC() function dropped $\mathrm{NO}_{2}$ and AOD from the model as it did not consider them to be significant. For Germany alone, the models performed poorly, with neither of the 3 independent variables considered to be more significant than the intercept.

Table 2 compares the AIC values of the beta regression models by including and excluding $\mathrm{AOD}$, along with $\mathrm{NO}_{2}$ and population density. It also shows the results of the Likelihood Ratio (LR) test and the Wald test performed on the two models to evaluate their performance. The significance level was set at 0.1. A $p$ value of less than 0.1 indicates that the unrestricted model (including AOD) is statistically better than the restricted one.

Again, the AOD appears to have some significance in three models. The AIC values improve, and the p-value suggests a significance too for Italy, Spain and Spain + Germany models. Similar tests were performed by excluding $\mathrm{NO}_{2}$ and population density. When investigating population density, 4 out of 7 model combinations had a $p$ value less than 0.1 indicating its statistical significance while $\mathrm{NO}_{2}$ displayed significance in 3 out of 7 models, as did AOD. For pre-exposure, the results indicate a greater significance for population density in the COVID-19 fatality rate than when the significance of AOD and $\mathrm{NO}_{2}$ was investigated in these countries. The results of these investigations are attached in the Supplementary Materials section (Tables S1, S2, S3, S4).

\subsection{Spatial Distributions of AOD during Complete Exposure Period}

Studies have shown that concentrations of both $\mathrm{NO}_{2}$ and AOD changed dramatically during the peak of the pandemic in countries like China and India. During this period, $\mathrm{NO}_{2}$ had a consistent decline across countries but AOD was impacted differently in different countries. China experienced an increase in AOD during the lockdown period while India recorded a decrease (Ghosh et al. 2020; Nichol et al. 2020; Ranjan et al. 2020). In view of this, $\mathrm{NO}_{2}$ and $\mathrm{AOD}$ data from Mar 1, 2020 to Jul 1, 2020 were also included in our analysis. This is the period when the coronavirus casecount had reached its peak. The AOD distributions during 
Table 1 Results of linear regression models (pre-exposure)

\begin{tabular}{|c|c|c|c|c|c|c|}
\hline & \multicolumn{3}{|l|}{$\mathrm{NO} 2 \_1+\mathrm{PD}$} & \multicolumn{3}{|c|}{$\mathrm{NO} 21^{\mathrm{a}}+\mathrm{PD}^{\mathrm{b}}+\mathrm{AOD} 1^{\mathrm{c}}$} \\
\hline & AIC & $R^{2}$ & Significant Variables & AIC & $R^{2}$ & Significant Variables \\
\hline Italy & -84.9894 & 0.3863 & NO2_1 & -86.8784 & 0.4651 & NO2_1, AOD_1 \\
\hline Germany & -96.06988 & 0 & Intercept & -96.06988 & 0 & Intercept \\
\hline Spain & -70.5783 & 0.3223 & PD & -72.2534 & 0.4106 & PD, AOD_1 \\
\hline Italy + Germany & -123.76349 & 0.0557 & PD & -123.76349 & 0.0557 & PD \\
\hline Italy + Spain & -155.85485 & 0.2962 & NO2_1, PD & -155.85485 & 0.2962 & NO2_1,PD \\
\hline Spain + Germany & -131.67629 & 0.4075 & NO2_1 & -137.45427 & 0.5135 & NO2_1, AOD_1 \\
\hline Italy + Germany + Spain & -191.25573 & 0.1208 & PD & -191.25573 & 0.1208 & $\mathrm{PD}$ \\
\hline
\end{tabular}

${ }^{a} \mathrm{NO} 2$ 1: $\mathrm{NO}_{2}$ from Dec 1, 2019-Feb 29, 2020

${ }^{\mathrm{b}} \mathrm{PD}$ : Population density

'AOD_1: AOD from Dec 1, 2020 to Feb 29, 2020

Table 2 Results of beta regression models (preexposure)

\begin{tabular}{lllll}
\hline & $\begin{array}{l}\text { NO2_1 +PD } \\
\text { AIC }\end{array}$ & $\begin{array}{l}\text { NO2_1+PD+AOD_1 } \\
\text { AIC }\end{array}$ & $\begin{array}{l}p \text { value } \\
\text { LR test }\end{array}$ & $\begin{array}{l}p \text { value } \\
\text { LR test }\end{array}$ \\
\hline Italy & -82.06926 & -84.82103 & 0.0293 & 0.0143 \\
Germany & -94.25607 & -93.09458 & 0.3598 & 0.357 \\
Spain & -72.14794 & -72.93206 & 0.0952 & 0.1096 \\
Italy + Germany & -129.39762 & -127.54315 & 0.7028 & 0.6772 \\
Italy + Spain & -157.35442 & -155.44147 & 0.768 & 0.7754 \\
Spain + Germany & -141.70877 & -145.03185 & 0.021 & 0.0283 \\
Italy + Germany + Spain & -195.77259 & -193.96108 & 0.6642 & 0.6657 \\
\hline
\end{tabular}

pre-exposure were displayed in Fig. 3. Figure 4 displays the spatial distributions of AOD in the atmosphere for the remainder period, which is Mar 1, 2020-Jul 1, 2020 in Italy, Germany and Spain.

There is a stark contrast between the AOD maps in Fig. 4 and the corresponding maps for the pre-exposure period (Fig. 3), especially over Italy and Spain, where the difference between the two periods appear to be larger. In Germany also there appears to be a slight increase in the AOD values from the pre-exposure period. This behavior appears similar to what was observed in China during the period when coronavirus cases were at their peak (Nichol et al. 2020).

\subsection{Regression Analysis During Complete Exposure for $\mathrm{NO}_{2}$ and AOD}

$\mathrm{NO}_{2}$ and AOD data are divided into two periods and included in the regression analysis. Data from Mar 1, 2020 to Jul 1, 2020 (NO2_2, AOD_2) is also included along with data from the pre-exposure period Dec 1, 2019-Feb 29, 2020 (NO2_1, AOD_1). Table 3 displays the AIC, adjusted $R^{2}$ values and the significant variables (from stepAIC()) for the linear regression models.

Multiple models selected AOD to be the significant variable and this is asserted in the increase of adjusted $R^{2}$ values for those models. AOD showed its significance in 4 out of 7 model combinations. In Italy and Italy + Germany, the higher values of AOD during the current period (AOD_2) were considered significant while for Spain and Spain + Germany, the lower values of AOD in the previous period (AOD_1) was considered significant in determining the coronavirus fatality rate. Table 4 displays the AIC results from the beta regression models along with the $p$ value from LR and the Wald tests for the same period as Table 3. The significance level was kept at 0.1 . Thus, a $p$ value less than 0.1 indicates that the unrestricted model (including AOD) performs statistically better than the restricted model.

Complementing the linear regression results, some beta regression results also display stronger significance when AOD is added to a model. The $p$ values from 4 out of 7 model combinations show significant contributions from AOD. Even the lower AIC values for those models suggest the same.

\section{Discussion}

The regression models showed results regarding the significance of AOD in statistically explaining COVID-19 fatality rates, along with $\mathrm{NO}_{2}$ and population density. The statistical 

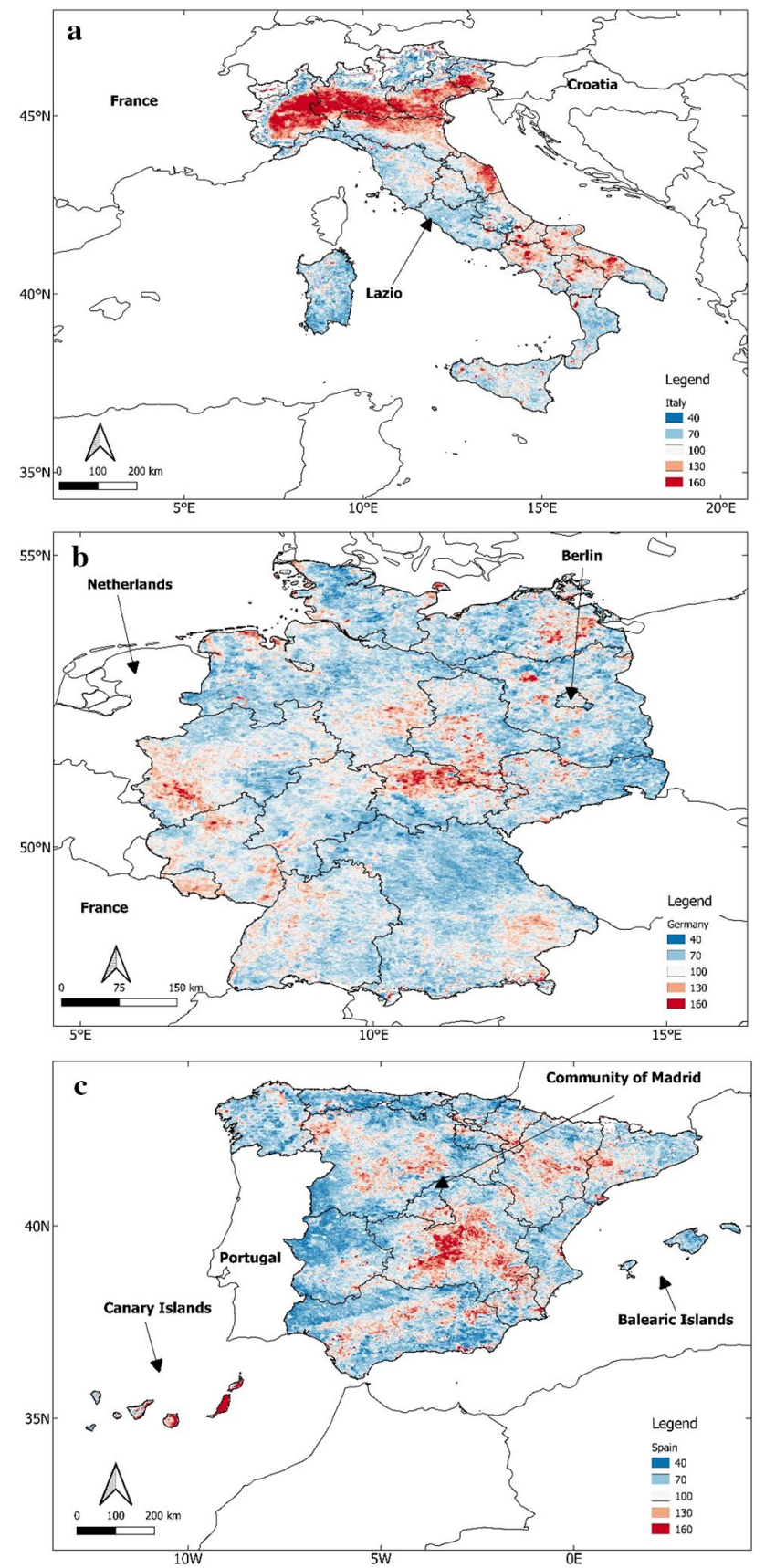

Fig. 4 Spatial Distributions of AOD extracted from MODIS for all regions in a Italy; b Germany; c Spain; from Mar 1, 2020 to Jul 1, 2020. The scale factor is 0.001 . The actual AOD values displayed in the figure are in the range of $0.04-0.16$. For Spain (c), the Canary Islands have been moved to fit in the figure

tests gave understandably mixed results in determining the significance of AOD, as environmental factors alone would not be expected to determine the fatality rate of a virus. The results from the complete exposure period (Dec 1, 2019-Jul $1,2020)$ displayed a stronger significance of AOD than the results from pre-exposure (Dec 1, 2019-Feb 29, 2020). From the complete exposure period, 4 out of 7 models selected $\mathrm{AOD}$ as a significant variable with a subsequent increase in the adjusted $R^{2}$ values too, indicating a better model when AOD was added as an independent variable to $\mathrm{NO}_{2}$ and population density. The AOD maps from the period (Mar 1, 2020-Jul 1, 2020) in Fig. 4 clearly show higher values of AOD than the maps from the pre-exposure period (Fig. 3). The results from the regression models during the complete exposure period are closely aligned with an article by Zhang et al. (2020) that discussed the indoor and outdoor airborne transmission of the coronavirus. Their study utilized space borne AOD measurements and was conducted for China, Italy and the United States of America (USA). It concluded that airborne transmissions do play a very important role in the spread of the virus. Though the AOD maps in Figs. 3 and 4 show that Germany has a decent prevalence of AOD, the models did not pick AOD as a significant variable there. In fact, the models did not pick $\mathrm{NO}_{2}$ and population density either when the regions in Germany alone were evaluated. It is known that these variables $\left(\mathrm{NO}_{2}\right.$, Population Density and AOD) alone would not fully determine the fatality rate of the coronavirus. Other important factors work in synergy to increase the potency of the coronavirus. In some regions, the synergy might have been achieved due to these other factors, and thus led to the results showing the significance of AOD in models involving Italy and Spain. During the complete exposure analysis, the 4 models out of 7 selected AOD to be a significant variable. This would be the most important result from this study; namely, that when the AOD values increased, the models displayed an increased significance of AOD in determining the coronavirus fatality rate. The models were not a great fit, which could be due to a relatively small number of samples, the omission of other confounding factors, and some anomalies being missed using mean values (over 3 months) of $\mathrm{NO}_{2}$ and AOD per region. However, the models still gave valuable information regarding the significance of the variables. Adding data from other countries in Europe, along with the addition of other important factors could help in generating a better model. Also, looking at the higher AOD values contributing to better model performance, it is suggested that a similar study could be explored in regions with very high AOD values like the Middle East and North Africa (MENA).

\section{Conclusion}

This study not only evaluated previous studies which showed that $\mathrm{NO}_{2}$ and population density are significant variables in determining COVID-19 fatality rates but also showed that AOD, used in conjunction with $\mathrm{NO}_{2}$ and population density, could help to improve the performance of the regression model to estimate COVID-19 fatality rate in regions with 
Table 3 Results of linear regression models (complete exposure)

\begin{tabular}{|c|c|c|c|c|c|c|}
\hline & \multicolumn{3}{|c|}{$\mathrm{NO} 2 \_1+\mathrm{NO} 2 \_2+\mathrm{PD}$} & \multicolumn{3}{|c|}{$\mathrm{NO} 2 \_1+\mathrm{NO}_{2} 2^{\mathrm{a}}+\mathrm{PD}+\mathrm{AOD} \_1+\mathrm{AOD} \_2^{\mathrm{b}}$} \\
\hline & AIC & $R^{2}$ & Variables & AIC & $R^{2}$ & Variables \\
\hline Italy & -86.12189 & 0.4444 & NO2_1, NO2_2 & -90.96363 & 0.5807 & NO2_1, NO2_2, AOD_2 \\
\hline Germany & -96.06988 & 0 & Intercept & -96.06988 & 0 & Intercept \\
\hline Spain & -70.5783 & 0.3223 & PD & -71.72448 & 0.393 & NO2_2, AOD_1 \\
\hline Italy + Germany & -152.45341 & 0.5852 & NO2_1, NO2_2 & -165.26975 & 0.7165 & NO2_1, NO2_2, AOD_2 \\
\hline Italy + Spain & -155.85485 & 0.2962 & NO2_1, PD & -155.85485 & 0.2962 & NO2_1, PD \\
\hline Spain + Germany & -134.15914 & 0.4493 & NO2_2 & -141.09301 & 0.5629 & NO2_2, AOD_1 \\
\hline Italy + Germany + Spain & -212.34928 & 0.4155 & NO2_1, NO2_2 & -212.34928 & 0.4155 & $\mathrm{NO} 2 \_1, \mathrm{NO} 2 \_2$ \\
\hline
\end{tabular}

${ }^{a} \mathrm{NO} 2 \_2: \mathrm{NO}_{2}$ from Mar 1, 2020 to Ju1 1, 2020

${ }^{\mathrm{b}}$ AOD_2: AOD from Mar 1, 2020 to Jul 1, 2020

Table 4 Results of beta regression models (complete exposure)

\begin{tabular}{lllll}
\hline & $\mathrm{NO}_{2 \_} 1+\mathrm{NO} 2 \_2+\mathrm{PD}$ & $\begin{array}{l}\mathrm{NO}_{2 \_} 1+\mathrm{NO} 2 \_2+\mathrm{PD}+ \\
\mathrm{AOD} \_1+\mathrm{AOD}_{-} 2\end{array}$ & $p$ value & $p$ value \\
& $\mathrm{AIC}$ & $\mathrm{AIC}$ & LR test & Wald test \\
\hline Italy & -83.32457 & -86.32696 & 0.0302 & 0.0125 \\
Germany & -92.96516 & -89.9271 & 0.6182 & 0.6251 \\
Spain & -70.18036 & -70.49765 & 0.1155 & 0.12 \\
Italy + Germany & -158.94446 & -167.82197 & 0.0016 & 0.0003 \\
Italy + Spain & -155.69081 & -151.73867 & 0.9764 & 0.9754 \\
Spain + Germany & -140.60018 & -143.37805 & 0.0337 & 0.0462 \\
Italy + Germany + Spain & -221.11899 & -218.81247 & 0.4288 & 0.4283 \\
\hline
\end{tabular}

high AOD. The results from this study open the door for further scientific studies, using advanced modeling techniques and more accurate data, to determine different environmental characteristics affecting the COVID-19 fatality rate.

Acknowledgements The first and second authors acknowledge the support from the Earth Systems Science and Data Solutions (EssDs) Lab and Computational and Data Sciences Graduate Program, Schmid College of Science and Technology, Chapman University.

\section{Compliance with Ethical Standards}

Conflict of Interest The author declares no known competing financial interests or personal relationships that could have appeared to influence the work reported in this paper.

Open Access This article is licensed under a Creative Commons Attribution 4.0 International License, which permits use, sharing, adaptation, distribution and reproduction in any medium or format, as long as you give appropriate credit to the original author(s) and the source, provide a link to the Creative Commons licence, and indicate if changes were made. The images or other third party material in this article are included in the article's Creative Commons licence, unless indicated otherwise in a credit line to the material. If material is not included in the article's Creative Commons licence and your intended use is not permitted by statutory regulation or exceeds the permitted use, you will need to obtain permission directly from the copyright holder. To view a copy of this licence, visit http://creativecommons.org/licenses/by/4.0/.

\section{References}

Antonietti R, Falbo P, Fontini F, et al (2020) The relationship between air quality, wealth, and COVID-19 diffusion and mortality across countries. SEEDS, Sustainability Environmental Economics and Dynamics Studies

Asadi S, Bouvier N, Wexler AS, Ristenpart WD (2020) The coronavirus pandemic and aerosols: does COVID-19 transmit via expiratory particles? Aerosol Sci Technol 54:635-638. https:// doi.org/10.1080/02786826.2020.1749229

Barcelo D (2020) An environmental and health perspective for COVID19 outbreak: meteorology and air quality influence, sewage epidemiology indicator, hospitals disinfection, drug therapies and recommendations. J Environ Chem Eng 8:104006. https://doi. org/10.1016/j.jece.2020.104006

Bendix A (2020) Coronavirus deaths in Italy and US could be up to double the official counts, new research shows. https://www.busin essinsider.com/actual-coronavirus-deaths-in-italy-us-higher-thanofficial-count-2020-5. Accessed 22 June 2020

Carleton T, Cornetet J, Huybers P et al (2020) Ultraviolet radiation decreases COVID-19 growth rates: global causal estimates and seasonal implications. SSRN J. https://doi.org/10.2139/ssrn.35886 01

Chudnovsky AA (2020) Letter to editor regarding Ogen Y 2020 paper: "Assessing nitrogen dioxide (NO2) levels as a contributing factor to coronavirus (COVID-19) fatality". Sci Total Environ. https:// doi.org/10.1016/j.scitotenv.2020.139236

Coccia M (2020) How high wind speed can reduce negative effects of confirmed cases and total deaths of COVID-19 infection in society. SSRN J. https://doi.org/10.2139/ssrn.3603380 
Cohen J (2020) Underreporting Of COVID-19 Coronavirus Deaths In The U.S. And Europe (Update). https://www.forbes.com/sites /joshuacohen/2020/04/14/underreporting-of-covid-19-deaths-inthe-us-and-europe/\#33abb87c82d7. Accessed 22 June 2020

Cribari-Neto F, Zeileis A (2009) Beta regression in R

EEA (2019) Air pollution country fact sheets 2019 - European Environment Agency. https://www.eea.europa.eu/themes/air/count ry-fact-sheets/2019-country-fact-sheets/. Accessed 22 Aug 2019

Ghosh S, Das A, Hembram TK et al (2020) Impact of COVID-19 induced lockdown on environmental quality in four indian megacities using landsat 8 OLI and TIRS-derived data and mamdani fuzzy logic modelling approach. Sustainability. https://doi. org/10.3390/su12135464

Gorelick N, Hancher M, Dixon M et al (2017) Google Earth Engine: planetary-scale geospatial analysis for everyone. Remote Sens Environ 202:18-27. https://doi.org/10.1016/j.rse.2017.06.031

Guo Z-D, Wang Z-Y, Zhang S-F et al (2020) Aerosol and surface distribution of severe acute respiratory syndrome coronavirus 2 in hospital wards, Wuhan, China, 2020. Emerg Infect Dis. https:// doi.org/10.3201/eid2607.200885

Lachmann A, Jagodnik KM, Giorgi FM, Ray F (2020) Correcting under-reported COVID-19 case numbers: estimating the true scale of the pandemic. medRxiv. https://doi. org/10.1101/2020.03.14.20036178

Lai S, Ruktanonchai NW, Zhou L et al (2020) Effect of non-pharmaceutical interventions to contain COVID-19 in China. Nature. https://doi.org/10.1038/s41586-020-2293-x

Lawton G (2020) Trials of BCG vaccine will test for COVID-19 protection. New Sci 246:9. https://doi.org/10.1016/S0262 $-4079(20) 30836-8$

Li Q, Guan X, Wu P et al (2020) early transmission dynamics in Wuhan, China, of novel coronavirus-infected pneumonia. N Engl J Med 382:1199-1207. https://doi.org/10.1056/NEJMoa2001316

Lyapustin A, Wang Y (2018) MCD19A2 MODIS/Terra + aqua land aerosol optical depth daily L2G Global $1 \mathrm{~km}$ SIN Grid V006 [data set]. NASA EOSDIS land processes DAAC

Mamedov T, Soylu I, Mammadova G, Hasanova G (2020) Sequence analysis and amino acid variations of structural proteins deduced from Novel Coronavirus SARS-CoV-2 strains, isolated in different countries. Life Sci

Masrur A, Yu M, Luo W, Dewan A (2020) Space-time patterns, change, and propagation of COVID-19 risk relative to the intervention scenarios in Bangladesh. Int J Environ Res Public Health 17:5911

Means C (2020) Mechanisms of increased morbidity and mortality of SARS-CoV-2 infection in individuals with diabetes: what this means for an effective management strategy. Metabolism 108:154254. https://doi.org/10.1016/j.metabol.2020.154254

Nichol JE, Bilal M, Ali M, Qiu Z (2020) Air pollution scenario over China during COVID-19. Remote Sens 12:2100

Ogen Y (2020a) Assessing nitrogen dioxide (NO2) levels as a contributing factor to coronavirus (COVID-19) fatality. Sci Total Environ 726:138605. https://doi.org/10.1016/j.scitotenv.2020.138605

Ogen Y (2020b) Response to the commentary by Alexandra A. Chudnovsky on 'Assessing nitrogen dioxide (NO) levels as a contributing factor to coronavirus (COVID-19) fatality.'. Sci Total Environ 5:10. https://doi.org/10.1016/j.scitotenv.2020.139239

Ranjan AK, Patra AK, Gorai AK (2020) Effect of lockdown due to SARS COVID-19 on aerosol optical depth (AOD) over urban and mining regions in India. Sci Total Environ 745:141024. https:// doi.org/10.1016/j.scitotenv.2020.141024

Sanchez-Lorenzo A, Vaquero-Martinez J, Lopez-Bustins J-A, et al (2020) Arctic oscillation: possible trigger of COVID-19 outbreak. arXiv:200503171 [physics, q-bio]

Setti L, Passarini F, De Gennaro G, et al (2020) The Potential role of Particulate Matter in the Spreading of COVID-19 in Northern
Italy: First Evidence-based Research Hypotheses. Public and Global Health

Travaglio M, Yu Y, Popovic R, et al (2020) Links between air pollution and COVID-19 in England. medRxiv

Tripathi A (2019) What is STEPAIC in R? https://ashutoshtripath i.com/2019/06/10/what-is-stepaic-in-r/. Accessed 2 July 2020

Veefkind JP, Aben I, McMullan K et al (2012) TROPOMI on the ESA Sentinel-5 Precursor: a GMES mission for global observations of the atmospheric composition for climate, air quality and ozone layer applications. Remote Sens Environ 120:70-83. https://doi. org/10.1016/j.rse.2011.09.027

Venables WN, Ripley BD (2002) Modern applied statistics with S. Springer, Fourth

Stephanie (2016a) Wald test: definition, examples, running the test. In: Statistics how to. https://www.statisticshowto.com/wald-test/. Accessed 19 Aug 2020

Stephanie (2016b) Likelihood-ratio tests (probability and mathematical statistics). In: Statistics how to. https://www.statisticshowto .com/likelihood-ratio-tests/. Accessed 18 Aug 2020

Zeileis A, Hothorn T (2002) Diagnostic checking in regression relationships

Zhang R, Li Y, Zhang AL et al (2020) Identifying airborne transmission as the dominant route for the spread of COVID-19. Proc Natl Acad Sci USA 117:14857. https://doi.org/10.1073/pnas.20096 37117

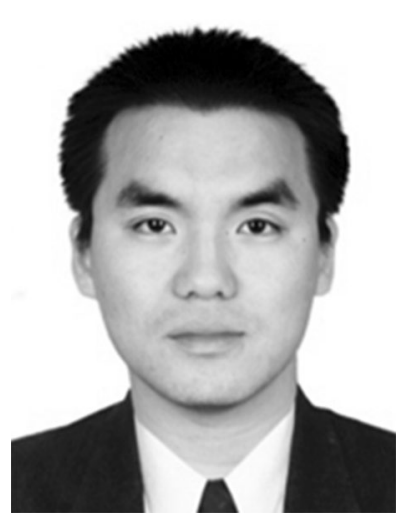

Wenzhao Li received the B.S. degree in Software and Digital Media Engineering from Shandong University, China, in 2011. He received M.S. degree in Telecom and Computer Networking from Northeastern University, Boston, MA, USA, in 2014. He received the $\mathrm{Ph} . \mathrm{D}$. degree in Computational and Data Sciences at Chapman University, CA, USA, in 2019. His research interests include remote sensing, oceanography, artificial intelligence and big data analysis. He has published more than 10 publications including peer-reviewed papers, full conference proceedings, and presented in international conferences such as AGU and EGU. He is a peer reviewer for several international journals such as Marine Pollution Bulletin and others.

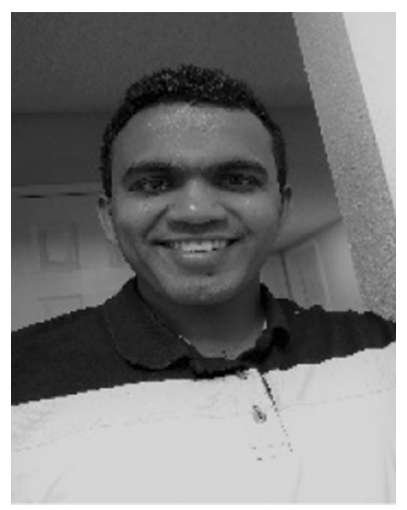

Rejoice Thomas received the B.Tech. degree in Mechanical Engineering from Karunya University, Coimbatore, India, in 2013. He received M.S. degree in Computational and Data Sciences from Chapman University, CA, USA, in 2020. He is currently pursuing $\mathrm{Ph} . \mathrm{D}$. degree from Computational and Data Sciences from Chapman University, CA, USA. His research interests include remote sensing, crop prediction, transfer learning, machine learning and drought monitoring. 


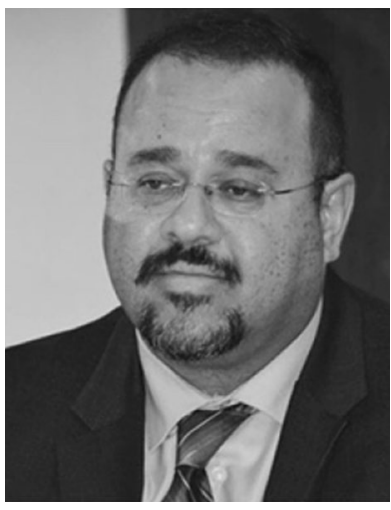

Hesham El-Askary received the B.S. degree in Physics with focus on Geophysics from Alexandria University, Alexandria, Egypt, in 1994. He received his two M.S. degrees in Earth Systems Science and Computational Science and Informatics as well as his Ph.D. with focus on Environmental Physics, from George Mason University, Virginia, USA, in 2003 and 2004, respectively. Since 2008, he has been with the Schmid College of Science and Technology, Chapman University, CA, USA and is currently a Professor of Earth Systems Science and Remote Sensing and serves as the program director for the Computational and Data Sciences graduate program, Chapman University, CA, USA. He also holds a Full Professor position at Faculty of Science, Alexandria University, Egypt (on leave). His research interests include modeling and observations of earth systems' processes with focus on natural disasters. He has published more than 100 publications including peer reviewed papers, book chapters, full conference proceedings and other conference papers. He is a peer reviewer for several international journals such as atmospheric chemistry and physics, remote sensing, IEEE transaction on geosciences and remote sensing and others. His work has been funded by NASA, USDA, NSF and EU.

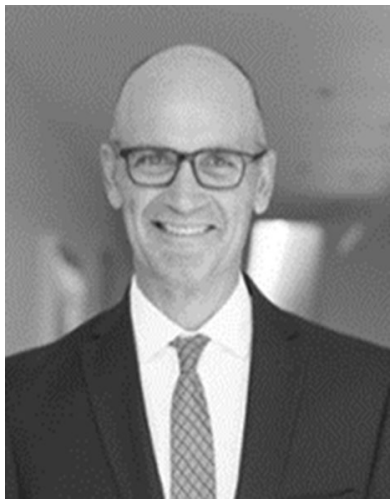

Thomas Piechota received the B.S. in Civil Engineering in 1989 from Northern Arizona University, his M.S. in Civil and Environmental Engineering in 1993 from UCLA, and his Ph.D. in Civil and Environmental Engineering in 1997 from UCLA. Dr. Piechota has been recognized for his efforts in teaching, research and as an administrator where he has helped advance the research enterprise through increases in research funding, outside partnerships and entrepreneurial activities. Dr. Piechota is the Vice President for Research and Professor of Environmental Science and Policy at Chapman University since 2016. In 2003, Dr. Piechota received a National Science Foundation CAREER Award for the project, "Improved Hydrologic Drought Forecasting Using Climate Information." From 2008-2013, Dr. Piechota was the Co-PI on a $\$ 20$ million National Science Foundation funded studies on climate change impacts in Nevada. Dr. Piechota was an invited Lead Author on the Southwest Chapter of the National Climate Assessment in 2013. Finally, Dr. Piechota was part of the 2013 Solar Decathlon team that took second place in world competition and first in the U.S. He has authored or coauthored more than 100 journal articles, book chapters, conference proceedings, and reports, and his work has been cited more than 3000 times. Dr. Piechota is a licensed Professional Engineer in the California. He has served on review panels for the National Science Foundation and various federal agencies. He has served on various professional and community committees including the American Society of Civil Engineers.

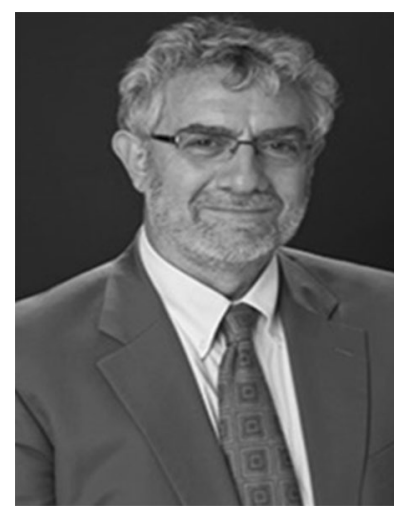

Daniele Struppa received the B.S. degree in Mathematics from the University of Milano, Italy, in 1977. He received his Ph.D. in Mathematics from the University of Maryland, College Park, in 1981 , with a dissertation on exponential representations for solutions of systems of convolution equations. He has been an Assistant Professor at the University of Milano (1981-1984), at the Scuola Normale Superiore in Pisa (1984-1987), and then a Full Professor of Mathematics at the University of Calabria (1987-1994), at George Mason University (1988-2006), and now at Chapman University since 2006. He is currently the President of Chapman University, where he also holds The Donald Bren Distinguished Presidential Chair in Mathematics. He has published more than 200 publications including several books, edited books, peer reviewed papers, book chapters, full conference proceedings and other conference papers. A paper he coauthored in 2016 received the Cozzarelli Prize from the National Academy of Sciences. Dr. Struppa is a managing editor for Quantum Studies: Mathematics and Foundations, and for the Hypercomplex section of Complex Analysis: Operator Theory. He a reviewer for several international journals and his work has been funded by NATO, NSF and EU.

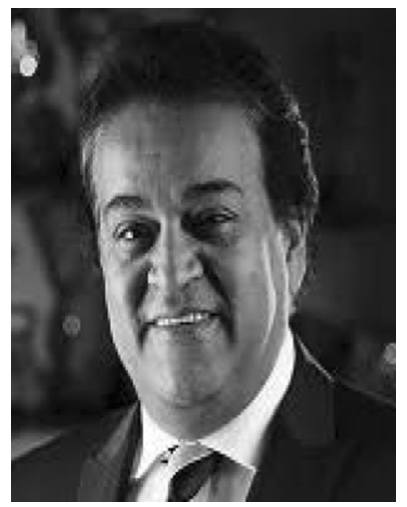

Khaled A. Abdel Ghaffar received the M.S. degree in Dental Surgery in 1989. He received his Ph.D. degree in Dental Surgery from Cairo University in 1995. Clinical instructor in undergraduate Periodontics, Faculty of Oral and Dental Medicine, Cairo University. He has been an assistant lecturer in undergraduate and graduate Periodontics, Oral Medicine and Oral Diagnosis, Faculty of Dentistry at Cairo University. He is also a visiting scholar and post graduate student, Department of Periodontics

University of Texas, Dental Branch, Houston, Texas, USA, along with being a lecturer of Oral Medicine, Oral Diagnosis and Periodontology, Cairo University. He has been an Associate Professor of Oral Medicine and Periodontology, Ain-Shams University and served as a Professor and Chairman of Oral Medicine and Periodontology, Ain-Shams University. He has been practicing General Dentistry since 1985 and has been training and teaching dental therapists and dental hygienists. Currently, he is the Minister of Higher Education and Scientific Research in Egypt. He has received numerous awards like IADR Edward Hatton Award for Best Research-Seattle Washington, USA, 1994, Unilever Travel Award Winner IADR Best research, USA, 1994, ranked second for best research, Euro-Perio Paris, France, 1994, ranked first for best research among Ain-Shams University, 1999, Distinguished National Medical Award Winner, National Academy for Scientific Research, 2001 and Academic Associate Fellow of the American Academy of Implant Dentistry, October 2015. 